\title{
Adenovirus-mediated Over-expression of the Cyclin/Cyclin-dependent Kinase Inhibitor, p21 Inhibits Vascular Smooth Muscle Cell Proliferation and Neointima Formation in the Rat Carotid Artery Model of Balloon Angioplasty
}

Mark W. Chang, * Eliav Barr, ${ }^{*}$ Min Min Lu, ${ }^{*}$ Kevin Barton, ${ }^{*}$ and Jeffrey M. Leiden ${ }^{\star *}$

${ }^{*}$ Departments of Medicine and ${ }^{\ddagger}$ Pathology, University of Chicago, Chicago, Illinois 60637

\begin{abstract}
Vascular smooth muscle cell (VSMC) proliferation after arterial injury is important in the pathogenesis of a number of vascular proliferative disorders, including atherosclerosis and restenosis after balloon angioplasty. Thus, a better understanding of the molecular mechanisms underlying VSMC proliferation in response to arterial injury would have important therapeutic implications for patients with atherosclerotic vascular disease. The $\mathbf{p 2 1}$ protein is a negative regulator of mammalian cell cycle progression that functions both by inhibiting cyclin dependent kinases (CDKs) required for the initiation of $S$ phase, and by binding to and inhibiting the DNA polymerase $\delta$ co-factor, proliferating cell nuclear antigen (PCNA). In this report, we show that adenovirus-mediated over-expression of human p21 inhibits growth factor-stimulated VSMC proliferation in vitro by efficiently arresting VSMCs in the G1 phase of the cell cycle. This p21-associated cell cycle arrest is associated both with significant inhibition of the phosphorylation of the retinoblastoma gene product $(\mathrm{Rb})$ and with the formation of complexes between p21 and PCNA in VSMCs. In addition, we demonstrate that localized arterial infection with a p21encoding adenovirus at the time of balloon angioplasty significantly reduced neointimal hyperplasia in the rat carotid artery model of restenosis. Taken together, these studies demonstrate the important role of p21 in regulating $\mathbf{R b}$ phosphorylation and cell cycle progression in VSMC, and suggest a novel cytostatic gene therapy approach for restenosis and related vascular proliferative disorders. (J. Clin. Invest. 1995. 96:2260-2268.) Key words: restenosis - gene therapy • adenovirus • vascular smooth muscle cells • cell cycle
\end{abstract}

\section{Introduction}

Vascular smooth muscle cells (VSMCs) ${ }^{1}$ play a critical role in the normal and pathological responses of the arterial wall to

Address correspondence to Jeffrey M. Leiden, $\mathrm{MD}, \mathrm{PhD}$, Department of Medicine, University of Chicago, 5841 S Maryland Ave., Chicago, IL 60637. Phone: 312-702-1919; FAX: 312-702-1385.

Received for publication 2 June 1995 and accepted in revised form 8 August 1995.

1. Abbreviations used in this paper: $\mathrm{CDK}$, cyclin-dependent kinase; PCNA, proliferating cell nuclear antigen; PFU, plaque forming units; PTCA, percutaneous transluminal coronary angioplasty; Rb, retinoblastoma; VSMC, vascular smooth muscle cells.

J. Clin. Invest.

(C) The American Society for Clinical Investigation, Inc.

0021-9738/95/11/2260/09\$2.00

Volume 96, November 1995, 2260-2268 injury (1). VSMCs are normally present in the arterial tunica media in the resting (G0) state where they regulate vascular tone and blood flow. Arterial injury leads to the proliferation of medial VSMCs and their subsequent migration from the media to the intima, where they proliferate and elaborate extracellular matrix ( $1-3)$. While this VSMC proliferative response is important in arterial wound healing, it also plays an important role in the pathogenesis of a number of cardiovascular diseases, including atherosclerosis and restenosis which occurs in 30$50 \%$ of patients following percutaneous transluminal coronary angioplasty (PTCA) (2-5). Molecular approaches designed to inhibit VSMC proliferation by targeting specific cell cycle regulatory pathways could both further elucidate the pathogenesis of vascular proliferative disorders and lead to the rational design of novel gene-based therapies for these diseases.

Previous studies have demonstrated that many growth factors can stimulate the proliferation of VSMCs in vitro and in vivo (4-8). However, the nuclear cell cycle regulatory mechanisms that govern the proliferative responses of VSMCs to growth factor stimulation and arterial injury have remained largely unknown. We have recently demonstrated that the retinoblastoma gene product $(\mathrm{Rb})$ is an important negative regulator of VSMC proliferation (9). In resting (G0/G1) VSMCs, $\mathrm{Rb}$ is present in the unphosphorylated form and, in that form, is a potent inhibitor of VSMC cell cycle progression. Phosphorylation (and inactivation) of $\mathrm{Rb}$ in response to growth factor stimulation is required for VSMC to traverse the G1/S checkpoint of the cell cycle and proliferate. Consistent with these findings, localized infection of the arterial wall with an adenovirus encoding a constitutively active nonphosphorylatable form of $\mathrm{Rb}$ significantly reduced medial VSMC proliferation and restenosis in two animal models of balloon angioplasty (9).

Although these previous studies clearly demonstrate the importance of $\mathrm{Rb}$ in controlling VSMC cell cycle progression, the molecular pathways that regulate $\mathrm{Rb}$ phosphorylation in VSMC remain unknown. Previous work in other cell types has suggested that the formation of cyclinD/cyclin-dependent kinase (CDK) complexes with serine/threonine kinase activity is required for both $\mathrm{Rb}$ phosphorylation, and for the ability of cells to traverse the G1/S checkpoint of the cell cycle (10-15). Moreover, cyclinD/CDK complexes can phosphorylate $\mathrm{Rb}$ in vitro leading to the suggestion that these complexes may directly regulate the phosphorylation and activity of $\mathrm{Rb}$ in response to growth factor stimulation $(14,15)$. The kinase activities of the cyclinD/CDK complexes can themselves be negatively regulated by several different molecules including $\mathrm{p} 16$, p21, and p27 (16-23). p21, also known as Cip 1 (CDK-interacting protein) (17), Sdi1 (senescent cell-derived inhibitor) (19), and WAF1 (wild-type p53-activated fragment) (20), is an important inhibitor of cell cycle progression in fibroblasts and also plays a critical role in protecting cells against certain types of injury. For example, UV-induced DNA damage leads 
to the induction of p53 which, in turn, activates transcription of p21, resulting in cell cycle arrest and DNA repair prior to $S$ phase-dependent chromosomal replication (24-26). Although p21 monomers can associate with active cyclinD/CDK complexes in proliferating fibroblasts (27), over-expression of p21 in such fibroblasts has been shown to potently inhibit the in vitro kinase activity of these cyclin/CDK complexes and to arrest these cells in the G1 phase of the cell cycle $(17-20,27)$ Thus, it has been suggested that p21 may inhibit cell cycle progression by inhibiting the cyclinD/CDK-dependent phosphorylation of $\mathrm{Rb}(17-20,27)$. However, to date this effect has not been demonstrated directly in mammalian cells. In addition to its ability to inhibit the kinase activities of cyclin/CDK complexes, p21 has also been reported to bind to and inhibit the activity of the DNA polymerase $\delta$ co-factor, PCNA (2830 ). Recent studies have suggested that different regions of the p21 protein are required for its CDK and PCNA inhibitory activities (30). Thus, p21 appears to inhibit cell cycle progression by at least two independent molecular mechanisms.

The cytostatic and cytoprotective activities of p21 led us to consider the hypothesis that forced over-expression of p21 might represent a novel means of modulating the pathologic proliferative response of VSMCs to arterial injury. In the studies described in this report, we have demonstrated that adenovirusmediated over-expression of p21 inhibits VSMC proliferation in response to serum stimulation in vitro. Moreover, we have shown that this effect is associated with a complete inhibition of $\mathrm{Rb}$ phosphorylation and with the formation of p21/PCNA complexes in the cells programmed to overexpress p21. Finally, localized infection of the arterial wall at the time of balloon angioplasty with a replication-defective adenovirus encoding p21 markedly inhibited restenosis in the rat carotid artery model of vascular injury. Taken together, these studies demonstrate the important role of p21 in regulating VSMC proliferation in vitro and in vivo, and suggest that adenovirus-mediated overexpression of p21 may represent a novel cytostatic gene therapy approach for restenosis and related vascular proliferative disorders.

\section{Methods}

Construction and purification of recombinant adenoviruses. Adp21 and AdlacZ are E1- and E3-deleted replication-defective adenovirus vectors derived from Ad5 sub360. Adp21 contains the human p21 cDNA (18) under the transcriptional control of the human elongation factor-1 $\alpha$ $(\mathrm{EF} 1 \alpha)$ gene promoter $(31)$ and the human $4 \mathrm{~F} 2$ heavy chain gene transcriptional enhancer (32). AdlacZ contains the bacterial lac $Z$ gene under the transcriptional control of the chicken $\beta$-actin gene promoter and the cytomegalovirus transcriptional enhancer (33). Both viruses were prepared and grown as high titer stocks in 293 cells as described previously (9). All virus stocks were purified by centrifugation in discontinuous $\mathrm{CsCl}$ gradients and dialyzed against a Hepes-buffered saline solution (9).

Cell culture and infection. Isolation and infection of primary rat aortic VSMCs were performed as described previously $(9,34)$ For measurements of cell proliferation, DNA synthesis, and cell cycle analysis passage 3 VSMCs were incubated in serum-free medium for $48 \mathrm{~h}$ before infection with either Adp21 or AdlacZ. This protocol results in $70-90 \%$ of the cultured cells accumulating in G0/G1 phases of the cell cycle as assessed by propidium iodide staining and FACS analysis (9). $24 \mathrm{~h}$ after infection, Adp21- or AdlacZ-infected cells were stimulated to proliferate by incubation in growth medium (45\% DME, $45 \%$ Hams F-12, and 10\% FBS) [GIBCO BRL, Grand Island, NY) (9). To assay $\left[{ }^{3} \mathrm{H}\right]$ thymidine incorporation, VSMCs were pulse-labeled for $4 \mathrm{~h}$ in growth medium containing methyl ${ }^{3} \mathrm{H}$ thymidine $(1 \mu \mathrm{Ci} / \mathrm{ml}, 2 \mathrm{Ci} / \mathrm{mmol}$; Amersham, Arlington Heights, IL) as described $(9,35)$. Each experiment was performed in triplicate in 6-well tissue culture plates (Falcon, Franklin Lakes, NJ).

Propidium iodide staining and FACS analysis. VSMCs were fixed overnight at $4^{\circ} \mathrm{C}$ with $75 \%$ ethanol and stained for $30 \mathrm{~min}$ at room temperature with propidium iodide $(50 \mu \mathrm{g} / \mathrm{ml})$. Cells were analyzed with a Becton Dickinson FACScan and CellFit software. A total of 4 $\times 10^{4}$ cells were counted for each sample.

Balloon angioplasty and adenovirus infection of rat carotid arteries. Adult male Sprague-Dawley rats were housed and cared for according to NIH guidelines in the Carlson animal facility of the University of Chicago. Localized infection of balloon-injured rat carotid arteries was performed as described previously (9). Briefly, Sprague-Dawley rats were subjected to balloon angioplasty of the left common carotid artery using a 2 French Fogarty catheter (36). Immediately following injury, $2 \times 10^{9} \mathrm{PFU}$ of Adp21 or AdlacZ in a total volume of $0.2 \mathrm{ml}$ was instilled into a $1-\mathrm{cm}$ segment of the distal common carotid artery for 5 min using a 24-gauge intravenous catheter.

Immunoprecipitation and immunoblot analyses. For immunoblot analysis of p21 expression in cultured cells, cell lysates were prepared as described previously $(9,37)$ and $100 \mu \mathrm{g}$ total protein from each sample was fractionated by SDS-PAGE in 15\% gels and subjected to immunoblot analysis using a rabbit polyclonal $\alpha$-p21 antibody (Pharmingen, San Diego, CA) (1:1,000 dilution). A peroxidase-labeled, goat $\alpha$-rabbit antiserum (1:3,000 dilution) (GIBCO BRL) was used in conjunction with the ECL chemiluminescence system (Amersham) for detection of bound primary antibody. For detection of p21/PCNA complexes in VSMCs, quiescent (G0/G1) primary rat aortic VSMCs were infected for $24 \mathrm{~h}$ with $40 \mathrm{PFU}$ per cell of AdlacZ or Adp21, stimulated to proliferate by incubation for $24 \mathrm{~h}$ in medium containing $10 \%$ FCS, and cell lysates were prepared in Tween lysis buffer $(50 \mathrm{mM}$ Hepes, $\mathrm{pH}=7.5,150 \mathrm{mM} \mathrm{NaCl}, 2.5 \mathrm{mM}$ EGTA, $1 \mathrm{mM}$ EDTA, $0.1 \%$ Tween20) $\left(1.5 \times 10^{6}\right.$ cells in $1 \mathrm{ml}$ of lysis buffer $)$. Cell lysates were precleared by incubation at $4^{\circ} \mathrm{C}$ for $1 \mathrm{~h}$ with $100 \mu \mathrm{l}$ of protein $\mathrm{A}$-sepharose beads (Pharmacia), mixed with $1 \mu \mathrm{l}$ of rabbit polyclonal $\alpha$-p21 antibody (Pharmingen), and incubated at $4^{\circ} \mathrm{C}$ for $60 \mathrm{~min}$. The resulting beads were washed three times in Tween lysis buffer, added to pre-cleared infected cell lysates containing $700 \mu \mathrm{g}$ of protein as determined with a commercially available kit (Pierce, Rockford, IL) and incubated for 60 $\min$ at $4^{\circ} \mathrm{C}$ with gentle rocking. The beads were washed three times with Tween lysis buffer and the immunoprecipitated proteins were released by boiling in SDS-PAGE loading buffer, fractionated by electrophoresis in $15 \%$ denaturing SDS polyacrylamide gels and subjected to immunoblot analyses using a polyclonal rabbit $\alpha$-p21 antibody $(1: 1,000$ dilution) (Pharmingen) or a mouse $\alpha$-PCNA mAb (1:100 dilution) (Santa Cruz, Santa Cruz, CA) as described above. For assessment of p21 expression in adenovirus-infected rat carotid arteries, arterial segments were harvested $4 \mathrm{~d}$ following balloon angioplasty and adenovirus infection as described (9). Two arterial segments infected with Adp21 and 2 segments infected with AdlacZ (60 mg total wet weight for each pair) were immediately placed in $200 \mu$ l of ice-cold homogenization buffer ( $100 \mathrm{mM} \mathrm{NaCl}, 1 \mathrm{mM}$ EDTA and $20 \mathrm{mM}$ Tris ( $\mathrm{pH} 8.0$ ), $1 \mathrm{mM}$ iodoacetamide, $0.23 \mathrm{mM}$ PMSF, $77 \mu \mathrm{M}$ aprotinin, $1 \mu \mathrm{M}$ leupeptin, 0.7 $\mu \mathrm{M}$ pepstatin $\mathrm{A}$, and $77 \mu \mathrm{M}$ benzamidine). After brief homogenization with a polytron homogenizer ( $5 \mathrm{~s} \mathrm{X} \mathrm{3)} \mathrm{on} \mathrm{ice,} 200 \mu \mathrm{l}$ of $2 \mathrm{X}$ SDSPAGE loading buffer (37) was added to each sample. $200 \mu \mathrm{g}$ of total protein from each sample was subjected to immunoblot analysis as described above using the $\alpha$-p 21 polyclonal antibody.

For assessment of $\mathrm{Rb}$ expression, passage 3 VSMCs cells were incubated in serum-free medium for $96 \mathrm{~h}$, infected with adenovirus as described above and, $24 \mathrm{~h}$ after infection, were stimulated to proliferate by incubation in growth medium. Cell lysates were prepared as described previously $(9,37)$ and protein corresponding to $5 \times 10^{5}$ cells from each sample was fractionated by electrophoresis in $7.5 \%$ SDS polyacrylamide gels and subjected to immunoblot analysis using an $\alpha$ - Rb monoclonal antibody (1:200 dilution) (Pharmingen) and a peroxidase-la- 
beled, goat $\alpha$-mouse IgG antiserum (1:2000 dilution) (Gibco/BRL) in conjunction with ECL chemiluminescence system (Amersham).

Histological assessment of restenosis. Rat carotid arteries were harvested $20 \mathrm{~d}$ after balloon injury and adenovirus infection as described previously (9). 5- $\mu \mathrm{m}$ sections from paraffin-embedded arteries were stained with hematoxylin and eosin and the neointimal and medial boundaries were determined on coded slides by an investigator blinded to the experimental conditions. Areas and ratios were determined by digital planimetry of tissue sections using the Image Pro-Plus image analysis system (Fryer Co, Chicago, IL). The I/M ratios were measured from six sections of each artery subjected to balloon angioplasty and adenovirus infection. The mean of these determinations was used to calculate the I/M cross-sectional ratios for each animal.

Statistical analysis. All values are expressed as mean \pm SEM. Statistical analyses were performed using Sigmaplot software (Jandel Scientific, Corte Madere, CA) on a Macintosh Power PC 8100 computer. The Student's $t$ test was used to evaluate differences between the experimental groups.

\section{Results}

Over-expression of p21 inhibits VSMC proliferation and cell cycle progression in response to growth factor stimulation in vitro. To directly test the effects of over-expression of p21 on cell cycle progression in VSMCs, we constructed a replicationdefective adenovirus, Adp21, that contains the human p21 cDNA (18) under the transcriptional control of the cellular elongation factor $1 \alpha$ gene promoter (31) and the $4 \mathrm{~F} 2$ heavy chain gene enhancer (32) (Fig. $1 A$ ). We have demonstrated previously that infection of primary cultured VSMC with 2040 plaque-forming units (PFU) per cell of such adenovirus vectors results in the transduction of $>90 \%$ of cultured VSMCs (9). To precisely define the levels and time course of p21 expression following infection with this virus, quiescent (G0/ G1) primary rat aortic VSMCs were infected with $20 \mathrm{PFU}$ per cell of either Adp21 or a control virus, AdlacZ that encodes the bacterial $\beta$-galactosidase enzyme (33). Cell lysates prepared 24-48 hours after infection were subjected to immunoblot analysis using a polyclonal antibody reactive with human p21. Adp21-infected VSMCs expressed markedly elevated levels of p21 as compared to both uninfected and AdlacZ-infected control cells (Fig. $1 \mathrm{~B}$ ). High levels of p21 expression were observed within 24 hours of infection and the levels of p21 expression increased further between 24 and $48 \mathrm{~h}$ after infection (data not shown). Of note, in some experiments, both uninfected and AdlacZ-infected cell lysates displayed low levels of expression of a $21 \mathrm{kD}$ protein that co-migrated with in vitro translated human p21 (Fig. $1 B$ ). This may reflect cross-reactivity of the polyclonal $\alpha$-human p21 antibody with the endogenous rat p21 expressed in these cells. In addition, all of the cell lysates contained a faint nonspecific band of slower mobility that crossreacted with the polyclonal $\alpha$-p 21 antiserum. From these experiment we concluded that Adp21 can be used to program highlevel p21 expression following infection of quiescent VSMCs in vitro.

To determine the effects of over-expression of p21 on growth factor-stimulated VSMC proliferation in vitro, primary rat VSMC were made quiescent by incubation for $48 \mathrm{~h}$ in serum free medium. This treatment reproducibly results in $70-90 \%$ of the cultured VSMCs becoming arrested in the G0/G1 phases of the cell cycle as assayed by propidium iodide staining and FACS analysis (9). The quiescent VSMC were infected with 10, 20, or $40 \mathrm{PFU}$ per cell of Adp21, and then stimulated to
A

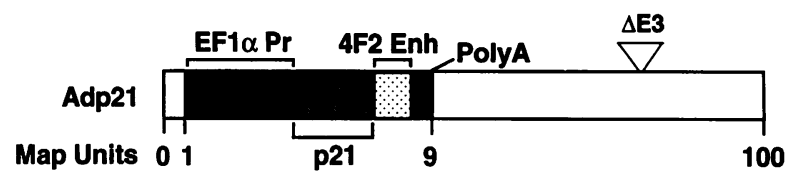

B
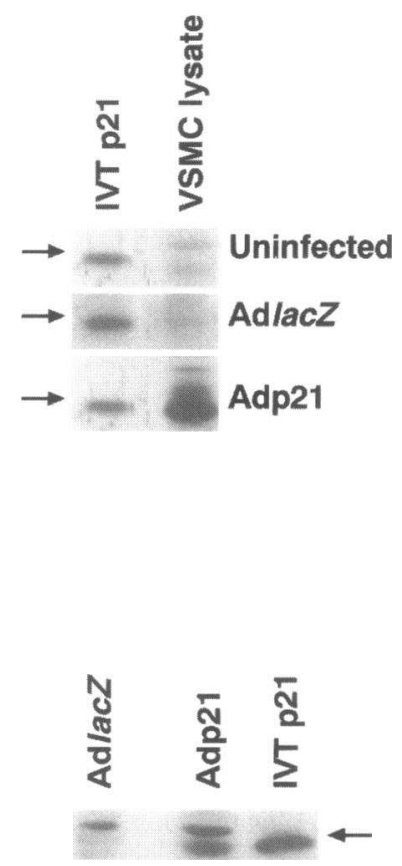

Figure 1. Expression of $\mathrm{p} 21$ in VSMCs and rat carotid arteries following infection with Adp21. ( $A$ ) Schematic representation of Adp21. Adp21 contains the human p21 cDNA (p21) under the transcriptional control of the human Elongation Factor $1 \alpha$ promoter (EFl $\alpha$ Pr) and the human $4 \mathrm{~F} 2$ heavy chain transcriptional enhancer (4F2 Enh). Adenovirus map units are shown below each map. $(B)$ Expression of p21 after infection of cultured rat aortic SMCs with Adp21. Cell lysates were prepared from cultured primary rat aortic SMCs $48 \mathrm{~h}$ after infection with $20 \mathrm{PFU}$ per cell of Adp21 or the AdlacZ control virus or from uninfected VSMCs and subjected to immunoblot analysis using an $\alpha$-p21 antiserum. (C) Expression of p21 after Adp21 infection of balloon-injured rat carotid arteries. Immediately after balloon angioplasty, rat carotid arteries were infected with $2 \times 10^{9} \mathrm{PFU}$ of Adp21 or AdlacZ. Lysates of the arteries were prepared $4 \mathrm{~d}$ after infection and subjected to immunoblot analysis using an $\alpha$-p21 antiserum. In vitro translated (IVT) p21 protein was included on the immunoblots in $B$ and $C$ as a marker. The positions of the $\mathrm{p} 21$ bands are indicated with arrows.

proliferate by exposure to medium containing $10 \%$ fetal calf serum (FCS). Control cells were infected with $40 \mathrm{PFU}$ per cell of AdlacZ. As shown in Fig. $2 A$, the AdlacZ-infected cells proliferated rapidly during the first $48 \mathrm{~h}$ after serum stimulation, undergoing approximately two doublings. In contrast, infection with Adp21 resulted in dose-dependent reductions in VSMC proliferation. At both the 24 and $48 \mathrm{~h}$ time points, each of the Adp21-infected cell cultures $(10,20$, and 40 PFU per cell) demonstrated significantly less proliferation than the control AdlacZ-infected cells $(\mathrm{P}<0.02)$. Infection with $40 \mathrm{PFU}$ per cell of Adp21 resulted in a $60 \%$ reduction in VSMC proliferation during the 48 hours after growth factor stimulation $(P$ 

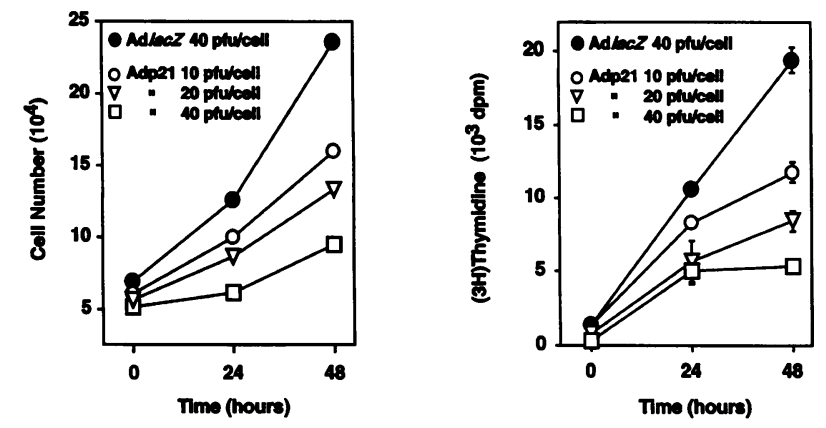

C

$\mathbf{O h}$

$24 \mathrm{~h}$

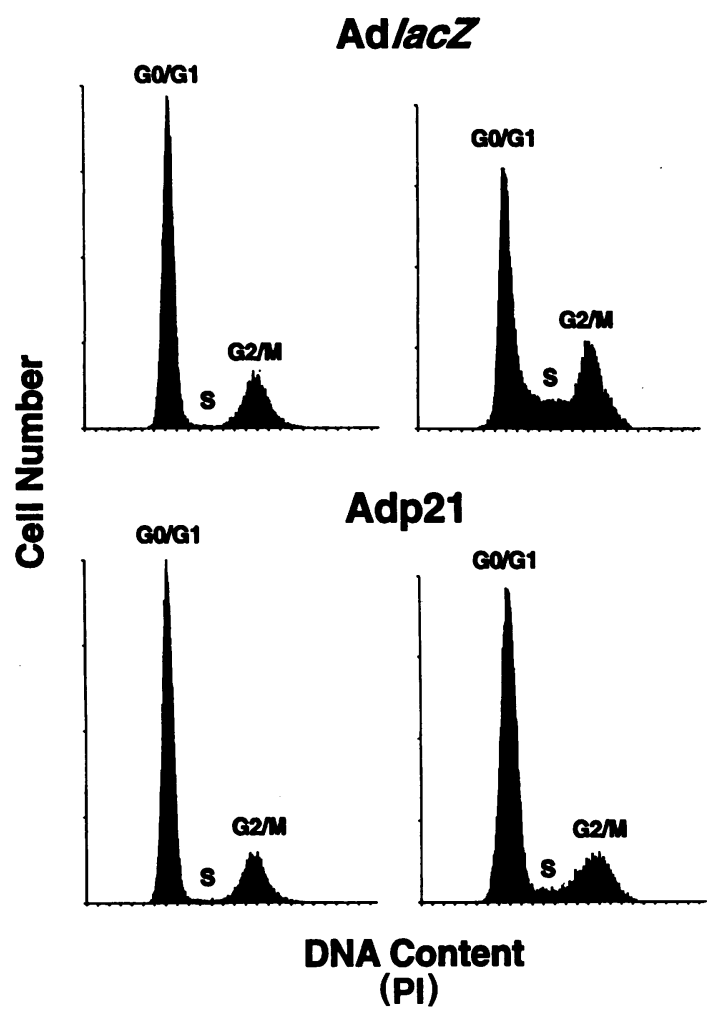

Figure 2. Inhibition of VSMC proliferation following infection with Adp21. (A) Replicate cultures of quiescent, serum-starved, rat aortic SMCs were infected with different amounts of Adp21 (open symbols) or AdlacZ (closed circles) and then stimulated to proliferate by incubation in $10 \%$ FCS. Cells were harvested 0,24 , and $48 \mathrm{~h}$ after serumstimulation and cell numbers determined using a hemocytometer. Cell viability as assessed by trypan blue exclusion was $>97 \%$ in all cultures at the end of the experiment. The data is shown as mean \pm SEM. Error bars are included on each data point but on some points are too small to be visualized. $(B)$ Replicate cultures of quiescent, serum-starved primary rat aortic SMCs were infected with either Adp21 (open symbols) or AdlacZ (closed circles) and then serum-stimulated as described in $A$. Cells were pulse-labeled for $4 \mathrm{~h}$ with $\left[{ }^{3} \mathrm{H}\right]$ thymidine and harvested 0,24 , and $48 \mathrm{~h}$ after serum-stimulation. The data are shown as mean $\left[{ }^{3} \mathrm{H}\right]$ thymidine incorporated \pm SEM. Error bars are included on each data point but in some cases are too small to be visualized. $(C)$ Replicate cultures of quiescent, serum-starved primary rat aortic SMCs were in-
$<0.0001$ ) (Fig. 2 A). Importantly, $>97 \%$ of both the AdlacZand Adp21-infected cells were viable at the end of these experiments as determined by trypan blue exclusion (data not shown). Thus, the inhibition of cell proliferation observed after Adp21 infection reflected a cytostatic as opposed to a cytotoxic effect.

If the observed decrease in proliferation produced by overexpression of p21 reflected its capacity to inhibit the kinase activities of cyclinD/CDK complexes, the Adp21-infected VSMCs should be arrested in the G1 phase of the cell cycle. This hypothesis was tested directly using two different experimental approaches. First, we measured DNA synthetic activity $\left(\left[{ }^{3} \mathrm{H}\right]\right.$ thymidine incorporation) after growth factor stimulation of both Adp21- and AdlacZ-infected primary rat aortic SMCs (Fig. $2 B$ ). Infection with Adp21 resulted in statistically significant $(P<0.05)$, dose-dependent reductions in $\left[{ }^{3} \mathrm{H}\right]$ thymidine incorporation which paralleled the decreased proliferative activity of these cells. Infection with $40 \mathrm{PFU} /$ cell of Adp21 led to a $>70 \%$ reduction in growth factor-stimulated $\left[{ }^{3} \mathrm{H}\right]$ thymidine incorporation as compared to the AdlacZ-infected control cells at $48 \mathrm{~h}(P<0.001)$ (Fig. $2 B)$. In a second set of experiments, quiescent VSMCs were infected with 40 PFU/cell of Adp21 or AdlacZ, and stimulated to proliferate by incubation in $10 \%$ FCS. Cell cycle progression was assayed by propidium iodide staining and FACS analysis (Fig. $2 \mathrm{C}$ ). Before serum stimulation $(0 \mathrm{~h}) 72 \%$ of the AdlacZ- and $71 \%$ of the Adp21-infected VSMCs were in the G0/G1 phases of the cell cycle. After $24 \mathrm{~h}$ of serum stimulation, $60 \%$ of the AdlacZinfected cells had progressed into the $\mathrm{G} 2 / \mathrm{M}+\mathrm{S}$ phases of the cell cycle (i.e., only $40 \%$ remained in $\mathrm{G} 0 / \mathrm{G} 1$ ). In contrast, $69 \%$ of the Adp21 infected cells remained in G0/G1. Thus, Adp21 infection resulted in a 15 -fold reduction in cell cycle progression during the first $24 \mathrm{~h}$ of serum stimulation. Similar results were observed 48 hours after serum stimulation. However, by this time point, the AdlacZ-infected cells were no longer synchrously dividing and many cells had traversed an entire cell cycle making precise quantitation of these samples difficult. Taken together, these results demonstrated that overexpression of p21 arrests VSMCs in G1, before entry into the $S$ phase of the cell cycle.

Over-expression of p21 inhibits the growth factor-stimulated phosphorylation of $R b$ in VSMCs. It has previously been suggested that one of the mechanisms by which over-expression of p21 might inhibit cell cycle progression is by interfering directly with the cyclinD/CDK-mediated phosphorylation of $\mathrm{Rb}(17-20,27)$. Although previous studies have shown that p21 can inhibit the cyclin/CDK dependent phosphorylation of $\mathrm{Rb}$ in vitro (17), a similar effect has not been demonstrated directly in mammalian cells. To test the effects of over-expression of $\mathrm{p} 21$ on $\mathrm{Rb}$ phosphorylation in response to growth factor stimulation, quiescent $(\mathrm{G} 0 / \mathrm{G} 1)$ primary rat VSMCs were infected with 40 PFU per cell of either Adp21 or AdlacZ, and then stimulated to synchronously enter and traverse the cell cycle by exposure to $10 \%$ FCS. The expression and phosphorylation of $\mathrm{Rb}$ after serum-stimulation was assessed by immu-

fected with 40 PFU/cell of either Adp21 or AdlacZ and then serumstimulated for $24 \mathrm{~h}$ as described in $A$. Cells were stained with propidium iodide and analyzed by FACS with a Becton Dickinson FACScan and CellFit software. 


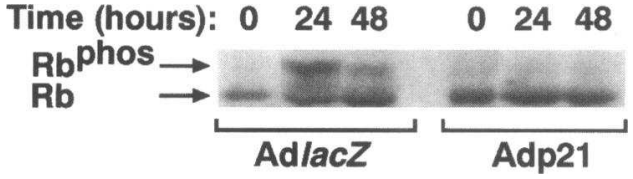

Figure 3. Over-expression of $\mathrm{p} 21$ inhibits Rb phosphorylation in growth factor stimulated VSMCs. Passage 3 primary rat aortic SMCs were arrested in the G0/G1 stages of the cell cycle by incubation in serumfree medium, infected with $40 \mathrm{PFU}$ per cell of AdlacZ or Adp21, and $24 \mathrm{~h}$ later stimulated to proliferate by incubation in medium containing $10 \%$ FCS. Cells were harvested 0,24 , and $48 \mathrm{~h}$ after serum-stimulation and cell lysates subjected to immunoblot analysis with an $\alpha-\mathrm{Rb} \mathrm{mAb}$ as described previously (9). Unphosphorylated ( $R b)$ and phosphorylated forms of $\mathrm{Rb}\left(\mathrm{Rb}^{\text {phos }}\right)$ are shown by arrows to the left of the autoradiogram.

noblot analysis of whole cell extracts (Fig. 3). As described previously, quiescent VSMCs contain only unphosphorylated $\mathbf{R b}$ (9). Serum stimulation, which results in the rapid progression of VSMCs into the $S$ phase of the cell cycle (9), was associated with the concomitant, progressive phosphorylation of $\mathrm{Rb}$ both in uninfected VSMC (data not shown) and in VSMCs infected with AdlacZ (Fig. 3). This finding was consistent with previous observations that have demonstrated an important role for $\mathrm{Rb}$ in regulating VSMC proliferation in response to growth factor stimulation (9). In contrast, infection of the quiescent VSMCs with Adp21 completely inhibited the growth factorstimulated phosphorylation of Rb. Even $48 \mathrm{~h}$ after serum stimulation, the preponderance of $\mathrm{Rb}$ in these cells remained in the unphosphorylated state (Fig. 3). These results demonstrated directly that over-expression of p21 results in decreased phosphorylation of $\mathrm{Rb}$ in vivo. When taken together with our previous finding that unphosphorylated Rb inhibits VSMC cell cycle progression at the G1/S checkpoint of the cell cycle (9), they suggested that the ability of p21 to inhibit VSMC proliferation in response to growth factor stimulation reflects, at least in part, its ability to inhibit the cyclin/CDK-mediated phosphorylation of $\mathrm{Rb}$.

A physical association between p21 and PCNA in Adp21 infected VSMCs. In addition to its ability to inhibit the kinase activities of cyclinD/CDK complexes, p21 can bind to and inhibit the activity of the DNA polymerase $\delta$ co-factor, PCNA (28-30). Inhibition of PCNA-dependent DNA synthesis may therefore reflect a second mechanism by which p21 inhibits cell cycle progression. Recent studies have demonstrated that different regions of the $\mathrm{p} 21$ protein are involved in binding to CDKs and PCNA, thereby suggesting that p21 may inhibit cell cycle progression by at least two distinct molecular mechanisms (30). To test directly whether overexpression of p21 in VSMCs results in the formation of p21/PCNA complexes, quiescent rat aortic SMCs were infected with 40 PFU per cell of Adp21 or Adlac $\mathrm{Z}$ and then stimulated to proliferate for $24 \mathrm{~h}$ by incubation in medium containing $10 \%$ FCS. Lysates prepared from these infected cells were immunoprecipitated with an $\alpha$-p21 antibody and the immunoprecipitates subjected to immunoblot analyses with either $\alpha$-p21 (Fig. 4, left) or $\alpha$-PCNA (Fig. 4, right) antibodies. Consistent with our previous experiments, (Fig. 2A) p21 was immunoprecipitated from the Adp21-infected but not from the AdlacZ-infected VSMCs (Fig. 4, left panel). More importantly, PCNA was co-immunoprecipitated with p21 from Adp21-infected but not from AdlacZ-infected VSMC lysates

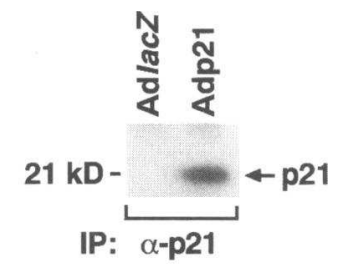

Immunoblot: $\alpha-p 21$

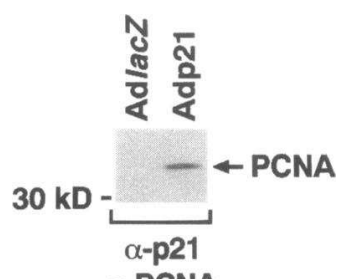

Figure 4. A physical association between p21 and PCNA in Adp21infected VSMCs. Quiescent (G0/G1) primary rat aortic smooth muscle cells were infected with 40 PFU per cell of Adp21 or AdlacZ. $24 \mathrm{~h}$ after infection, cells were stimulated to proliferate by incubation in medium containing $10 \%$ FCS. Cell lysates prepared $24 \mathrm{~h}$ after stimulation were immunoprecipitated with an $\alpha$-p21 antibody and the resultant immunoprecipitates were subjected to immunoblot analysis with $\alpha$-p21 (left) or $\alpha$-PCNA ( right) antibodies. PCNA was co-immunoprecipitated with p21 in the Adp21- but not in the AdlacZ-infected VSMCs. Size markers in $\mathrm{kD}$ are shown to the left of each autoradiogram.

(Fig. 4, right panel). Thus, p21 forms complexes with PCNA following Adp21 infection of VSMCs.

Over-expression of p21 inhibits neointimal hyperplasia in the rat carotid artery injury model of restenosis. The rat carotid artery balloon injury model represents a well-characterized, highly reproducible vascular proliferative disorder that is dependent on VSMC proliferation and migration $(9,36,38-40)$. Previous studies using this model have demonstrated that medial VSMC proliferation begins within 2 days of arterial injury, reaching a peak within $4 \mathrm{~d}$. By $20 \mathrm{~d}$ after balloon angioplasty, nearly all of the injured arteries develop a stable neointimal lesion and demonstrate no evidence of VSMC proliferation in either the neointima or the media of the vessel wall $(9,36$, 38-40).

To determine directly the effects of p21 over-expression on neointima formation, rat carotid arteries were subjected to balloon angioplasty and immediately infected with $2 \times 10^{9} \mathrm{PFU}$ of either Adp21 or AdlacZ. We have previously demonstrated that this protocol results in the transduction of $>70 \%$ of the medial VSMC in the injured arterial segment (9). To demonstrate over-expression of recombinant p21 in these experiments, injured arterial segments were harvested $4 \mathrm{~d}$ after infection and crude lysates prepared from these arteries were assayed for $\mathrm{p} 21$ expression by immunoblot analysis. As seen in Fig. $1 C$, arteries infected with Adp21 expressed markedly elevated levels of p21 as compared to the AdlacZ-infected arteries. Immunoblots from the AdlacZ- and Adp21-infected arteries contained equivalent levels of a second band of slower mobility. This band did not represent native rat $\mathrm{p} 21$ because native rat $\mathrm{p} 21$ migrates with identical mobility to human p21 in our SDS-PAGE conditions (see Fig. $1 B$ ). However, it may represent a denatured form of rat p21 or, alternatively non-specific binding of the antibody reagents used in these immunoblots.

In a second series of experiments, rat carotid arteries were subjected to balloon angioplasty and immediately infected with $2 \times 10^{9} \mathrm{PFU}$ of either Adp21 or AdlacZ. Arteries were harvested $20 \mathrm{~d}$ after balloon injury and restenosis, as determined by the neointima/media (I/M) area ratio, was assessed by digital planimetry. Carotid arteries from the AdlacZ-infected control arteries displayed an I/M ratio of $1.01 \pm 0.04(n=5)$. In contrast, infection with Adp21 resulted in an I/M ratio of $0.54 \pm 0.11$ $(n=6)$, a $46 \%$ reduction as compared to the AdlacZ control 

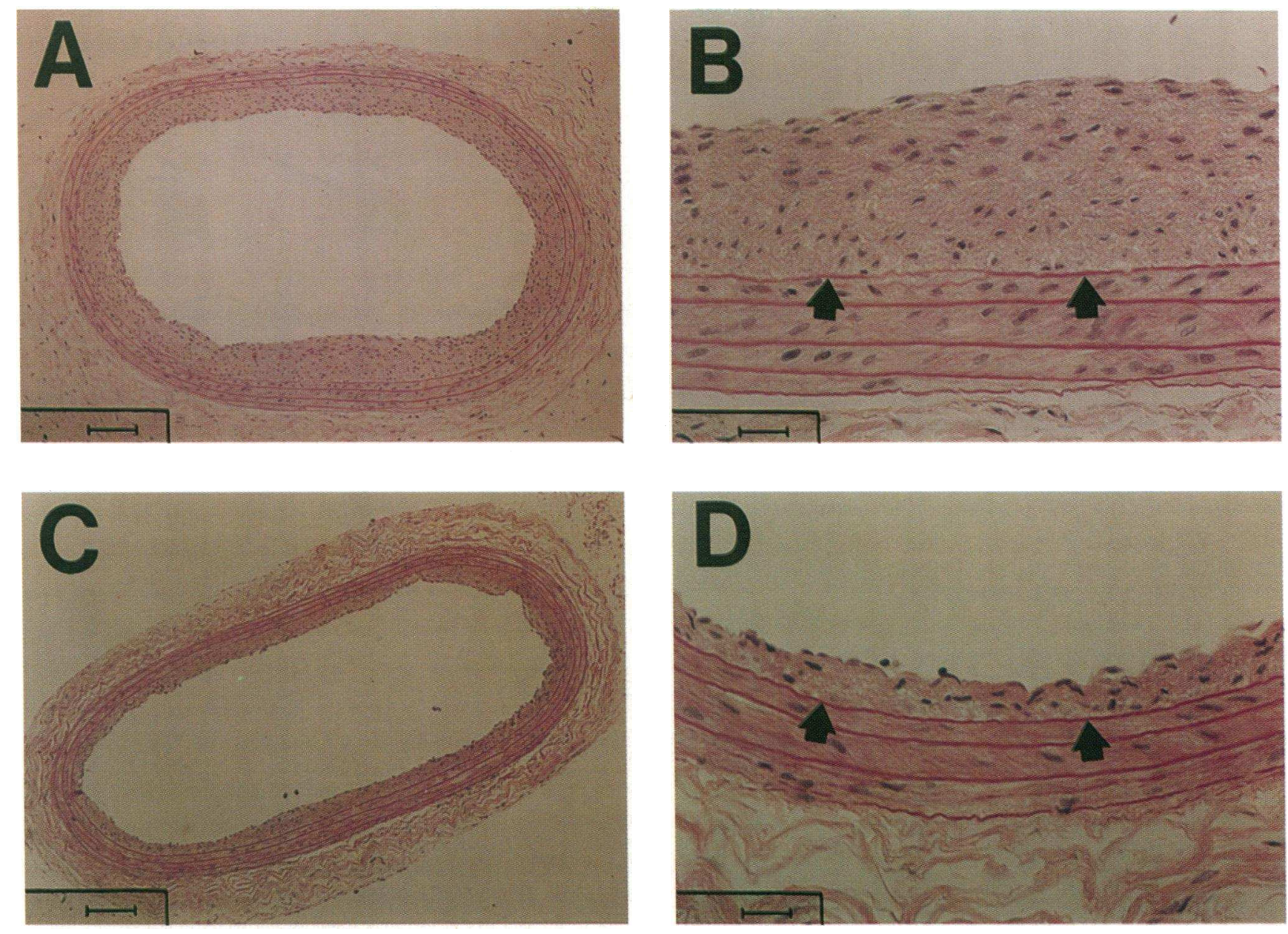

$E$

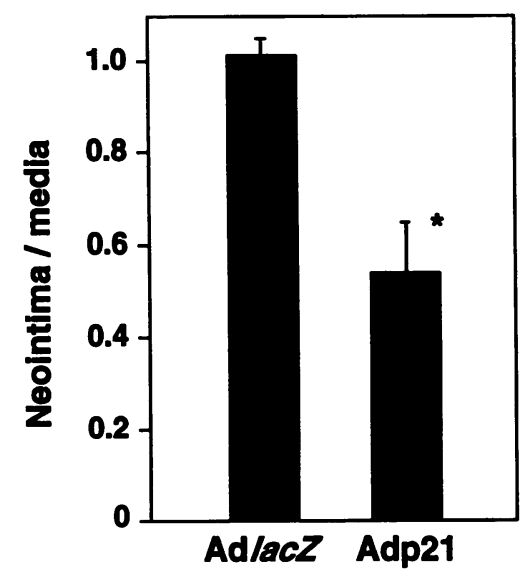

Figure 5. Inhibition of neointima formation by Adp21 infection following balloon angioplasty in the rat carotid artery injury model. $(A-D)$ Representative photomicrographs of rat carotid arteries $21 \mathrm{~d}$ following balloon injury and infection with $2 \times 10^{9}$ PFU of AdlacZ ( $A$ and $B$ ) or Adp21 ( $C$ and $D$ ). Arrows denote the internal elastic lamina which separates the medial and intimal layers of the arterial wall. The bars are equivalent to $640 \mu \mathrm{M}$ in $A$ and $C$ and to $50 \mu \mathrm{M}$ in $B$ and $D$. (E) Neointima formation in Adp21- and AdlacZ-infected rat carotid arteries $20 \mathrm{~d}$ after balloon angioplasty. Immediately following balloon injury, rat carotid arteries were infected with $2 \times 10^{9} \mathrm{PFU}$ of either the AdlacZ control virus ( $n$ $=5)$ or Adp21 $(n=6) .20 \mathrm{~d}$ after injury, the cross-sectional areas of the neointima and media were measured by digital planimetry in representative sections of the injured vessels. The data are shown as mean \pm SEM. An asterisk signifies difference $(P<0.001)$ as compared to AdlacZ-infected vessels.

group ( $P<0.001)$ (Fig. 5). Thus, localized infection with a replication-defective adenovirus encoding human p21 at the time of arterial injury resulted in a significant reduction in neointima formation in the rat carotid artery model of VSMC proliferation and restenosis.

Several experiments were performed to assess the safety of localized arterial infection with Adp21. First, necropsies per- formed by an independent pathologist did not reveal any evidence of gross or microscopic tissue pathology in the Adp21infected rats. Moreover, serum electrolytes, renal and liver function tests, complete blood counts and clotting parameters were all normal 20 days after balloon angioplasty and Adp21 infection (data not shown). Finally, as shown in Figs. 5, $C$ and $D$ there was no evidence of localized arterial inflammation, necro- 
sis or aneurysm formation in the Adp21-infected arteries $20 \mathrm{~d}$ after balloon angioplasty.

\section{Discussion}

Mammalian cells have evolved a set of specific and distinct molecular responses to pathologic stimuli. Some cells including VSMCs, fibroblasts, and lymphocytes proliferate in response to injury and foreign pathogen invasion. In other cases, such as UV-induced DNA damage or exposure to steroids, these same cells can undergo cell cycle arrest and even apoptotic cell death. Although largely adaptive, these responses to injury are in some cases pathological, leading to a variety of human diseases. Thus, for example, dysregulated cell proliferation has been associated with both autoimmune disease (41) and malignancy (42). Similarly, inappropriate apoptotic cell death may be associated with a variety of neurodegenerative disorders (43). In the case of VSMCs, unregulated cell proliferation in response to arterial injury has been implicated in the etiology of a variety of vascular proliferative diseases including atherosclerosis and restenosis following balloon angioplasty (2-5).

The plasticity of injury responses in a single cell type suggested to us that it might be possible to manipulate these responses by over-expressing specific molecules involved in regulating these pathways. In the studies described in this report, we have shown that over-expression of one such molecule, the cyclin/CDK inhibitor, p21 can fundamentally alter the proliferative responses of VSMCs to growth factors in vitro and to arterial injury in vivo. Adenovirus-mediated over-expression of p21 arrested VSMCs in G1, and significantly decreased VSMC proliferation. These growth inhibitory effects were associated both with an inhibition of $\mathrm{Rb}$ phosphorylation in these cells and with the formation of $\mathrm{p} 21 / \mathrm{PCNA}$ complexes. In addition, adenovirus-mediated over-expression of p21 in the arterial wall at the time of balloon angioplasty significantly inhibited neointima formation in the rat carotid artery model of restenosis. These findings have a number of basic scientific and therapeutic implications.

Previous studies have demonstrated important roles for two tumor suppressor genes, p53 and $\mathrm{Rb}$ in negatively regulating VSMC proliferation in vitro and in vivo $(9,44)$. It is also known that p53 can activate transcription of p21 in several cell types $(20,24,25)$ Moreover, over-expression of p21 can directly inhibit the kinase activities of cyclinD/CDK complexes and the activity of PCNA in vitro $(17-20,27)$. When taken together with our finding that over-expression of p21 $(a)$ leads to the formation of $\mathrm{p} 21$ /PCNA complexes, $(b)$ inhibits Rb phosphorylation, and $(c)$ inhibits cell cycle progression in VSMCs, these findings define a distal regulatory pathway for VSMC proliferation in response to growth factors and arterial injury (Fig. 6). Future studies designed to examine how specific growth factor receptors modulate this cell cycle regulatory pathway in VSMCs should allow the construction of a complete map of the pathways leading from cell-surface receptors to nuclear cell cycle regulatory molecules in these cells.

In addition to defining the molecular pathways underlying VSMC proliferation, our findings also have clinical significance. Coronary artery disease (CAD) due to atherosclerosis is the leading cause of morbidity and mortality in the United States. PTCA remains a mainstay of therapy for symptomatic CAD, with more than 400,000 procedures expected in 1995 in the United States alone. While the procedure is initially successful
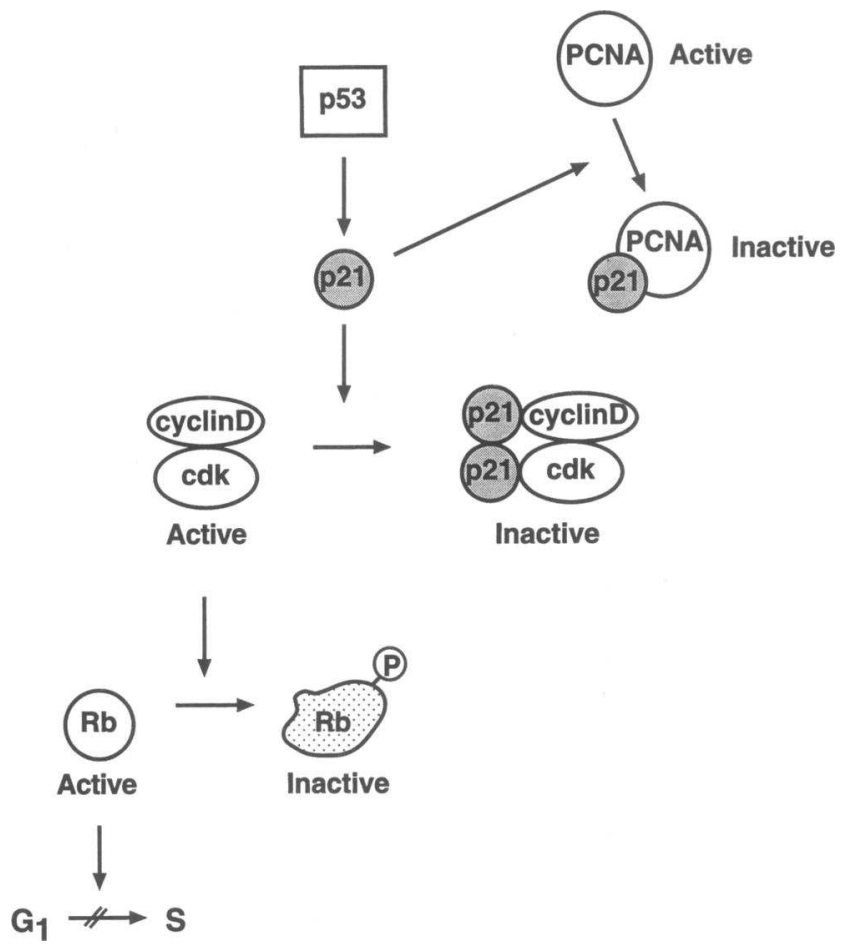

Figure 6. The distal cell cycle regulatory pathway in VSMC. Schematic illustration of a portion of the regulatory pathway controlling the G1 to $\mathrm{S}$ transition of the cell cycle in VSMC. p53 is known to upregulate p21 transcription. p21 inhibits the kinase activity of the cyclinD/CDK complexes. cyclinD/CDK complexes in their active forms phosphorylate $(P)$ and inactivate the retinoblastoma protein $(R b)$. In its unphosphorylated form, Rb inhibits (\|) VSMCs from traversing the G1 to S checkpoint of the cell cycle. p21 also binds to the DNA polymerase $\delta$ cofactor, PCNA and inhibits its activity.

in relieving arterial stenoses in the vast majority of patients, clinically significant restenosis continues to complicate the procedure in up to $40 \%$ of cases (2-5). Numerous pharmacologic strategies including antiplatelet agents, anticoagulants, angiotensin-converting enzyme inhibitors and cytotoxic agents have failed to significantly reduce the rate of restenosis following PTCA (45-49). Recently, a number of gene based therapies for restenosis have been described $(9,39,40,50-52)$. Adenovirusmediated transfer of the herpes simplex virus thymidine kinase gene (HSV-tk) followed by the systemic administration of ganciclovir has been shown to inhibit restenosis in both the rat and pig models of arterial injury $(39,40,52)$. Although effective, there are several disadvantages of this cytotoxic approach as compared to cytostatic gene therapy using p21. First HSV-tk therapy involves the induction of VSMC death which is associated with concomitant intravascular inflammation and the potential for medial necrosis and aneurysm formation. In addition, this approach requires systemic ganciclovir therapy, which has been associated with neutropenia, thrombocytopenia, and ventricular arrhythmias in humans $(53,54)$. Biopolymer-mediated delivery of antisense oligonucleotides directed to c-myb or PCNA and cdc2, have also both been reported to inhibit neointimal hyperplasia in the rat carotid artery injury model $(50,51)$. However, recent studies have suggested that antisense oligonucleotides may cause degradation of multiple RNA species and have important non-specific effects on intracellular and cell 
surface proteins (55-57). In addition, antisense oligonucleotides may be subject to significant batch-to-batch variability and to date it has been impossible to efficiently deliver antisense oligonucleotides to the vascular wall using nonviral, catheter mediated approaches (55-57). Finally, adenovirus mediated over-expression of a non-phosphorylatable constitutively active form of $\mathrm{Rb}(\mathrm{HA} \Delta \mathrm{Rb})$ has also been shown to significantly reduce restenosis in both the rat carotid and pig iliofemoral artery models of balloon angioplasty (9).

A cytostatic gene therapy approach using catheter-mediated delivery of Adp21 offers a clinically applicable, effective and non-toxic treatment for vascular proliferative disorders. The degree of inhibition of restenosis achieved by Adp21 gene transfer in our studies $(46 \%)$ was comparable to that achieved with over-expression of $\mathrm{HA} \Delta \mathrm{Rb}(9)$, as well as with HSV-tk gene transfer with systemic ganciclovir therapy $(39,40,52)$, and the intraluminal delivery of antisense oligonucleotides $(50,51)$. Furthermore, administration of Adp21 was not associated with significant inflammatory responses nor with clinical toxicity in the present study. From a clinical standpoint, the fact that Adp21 appears to inhibit two proliferative pathways (cyclin/CDKs and PCNA) may make it a more potent cytostatic agent than Ad$\mathrm{HA} \triangle \mathrm{Rb}$. On the other hand, the more pleiotropic activities of Adp21 may result in more undesirable side effects in vivo. It is also possible that co-administration of $\operatorname{Adp} 21$ and $\operatorname{AdHA} \triangle \mathrm{Rb}$ may prove to be more efficacious than the administration of either virus alone. The resolution of these questions will await the results of further pre-clinical trials which are currently in progress. Finally, because cyclin/CDK kinases are important regulators of proliferation in a wide variety of cell types, adenovirus mediated over-expression of p21 may prove useful for the treatment of other human diseases associated with dysregulated cell proliferation. Similarly, the finding that over-expression of both $\mathrm{p} 21$ and $\mathrm{Rb}$ can be used to provide effective cytostatic gene therapy suggests that other cell cycle regulatory molecules such as p15 or p27, either alone, or in combination may represent useful cytostatic gene therapy reagents.

\section{Acknowledgments}

This work was supported in part by a grant from the National Heart, Lung and Blood Institute (1R01HL54592-01) to J. M. Leiden and a gift from the Falk Trust.

\section{References}

1. Ross, R. 1993. The pathogenesis of atherosclerosis: a perspective for the 1990's. Nature (Lond.) 362:801-809.

2. Forrester, J. S., M. Fishbein, R. Helfant, and J. Fagin. 1991. A paradigm for restenosis based on cell biology: clues for the development of new preventive therapies. J. Am. Coll. Cardiol. 17:758-769.

3. Ip, J. H., V. Fuster, L. Badimon, J. Badimon, M. B. Taubman, and J. H Chesebro. 1990. Syndromes of accelerated atherosclerosis: role of vascular injury and smooth muscle cell proliferation. J. Am. Coll. Cardiol. 15:1667-1687.

4. Schwartz, R. S., D. R. Holmes, and E. J. Topol. 1992. The restenosis paradigm revisited: an alternative proposal for cellular mechanisms. J. Am. Coll. Cardiol. 20:1284-1293.

5. Liu, M. W., G. S. Roubin, and S. B. King. 1989. Restenosis after coronary angioplasty. Potential biologic determinants and role of intimal hyperplasia. Circulation. 79:1374-1387.

6. Fingerle, J., R. Johnson, A. W. Clowes, M. W. Majesky, and M. A. Reidy. 1989. Role of platelets in smooth muscle cell proliferation and migration after vascular injury in rat carotid artery. Proc. Natl. Acad. Sci. USA. 86:8412-8416.

7. Libby, P., D. Schwartz, E. Brogi, H. Tanaka, and S. K. Clinton. 1992 A cascade model for restenosis: A special case of atherosclerosis progression. Circulation. 86 ( suppl III):III-47-III-52.
8. Barr, E., and J. M. Leiden. 1994. Somatic gene therapy for cardiovascular disease: Recent advances. Trends. Cardiovasc. Med. 4:57-63.

9. Chang, M. W., E. Barr, J. Seltzer, Y. Q. Jiang, G. J. Nabel, E. G. Nabel. M. S. Parmacek, and J. M. Leiden. 1995. Cytostatic gene therapy for vascular proliferative disorders with a constitutively active form of the retinoblastoma gene product. Science (Wash. DC). 267:518-522.

10. Nasmyth, K. 1993. Control of the yeast cell cycle by the Cdc28 protein kinase. Curr. Opin. Cell Biol. 5:166-179.

11. Hinds P. W., S. Mittnacht, V. Dulic, A. Arnold, S. I. Reid, and R. A. Weinberg. 1992. Regulation of retinoblastoma protein functions by ectopic expression of humans cyclins. Cell. 70:993-1006.

12. Ewen, M. E., H. K. Sluss, C. J. Sherr, H. Matsushime, J. Kato, and D. M. Livingston. 1993. Functional interactions of the retinoblastoma protein with mammalian D-type cyclins. Cell. 73:487-497.

13. Dowdy, S. F., P. W. Hinds, K. Louie, S. I. Reed, A. Arnold, and R. A. Weinberg. 1993. Physical interaction of the retinoblastoma protein with human D cyclins. Cell. 73:499-511.

14. Matsushime, H., M. E. Ewen, D. K. Strom, J. Y. Kato, S. F. Hanks, M. F. Roussel, and C. J. Sherr. 1992. Identification and properties of an atypical catalytic subunit (p34 ${ }^{\text {PSK-J3 } / C D K 4) ~ f o r ~ m a m m a l i a n ~ D ~ t y p e ~ G 1 ~ c y c l i n s . ~ C e l l . ~ 71: 323-334 . ~}$

15. Kato, J., H. Matsushime, S. W. Hiebert, M. E. Ewen, and C. J. Sherr 1993. Direct binding of cyclin $\mathrm{D}$ to the retinoblastoma gene product $(\mathrm{pRb})$ and $\mathrm{pRb}$ phosphorylation by the cyclin D-dependent kinase CDK4. Genes \& Dev 7:331-342.

16. Serrano, M., G. H. Hannon, and D. Beach. 1993. A new regulatory motif in cell-cycle control causing specific inhibition of cyclin D/CDK4. Nature (Lond.) 366:704-707.

17. Harper, J. W., G. R. Adami, N. Wei, K. Keyomarsi, and S. J. Elledge. 1993. The p21 CDK-interacting protein cipl is a potent inhibitor of G1 cyclindependent kinases. Cell. 75:805-816.

18. Xiong, Y., G. J. Hannon, H. Zhang, D. Casso, R. Kobayashi, and D. Beach. 1993. p-21 is a universal inhibitor of cyclin kinases. Nature (Lond.) 366:701-704

19. Noda, A., Y. Ning, S. F. Venable, O. M. Pereira-Smith, and J. R. Smith 1994. Cloning of senescent cell-derived inhibitors of DNA synthesis using an expression screen. Exp. Cell Res. 211:90-98.

20. El-Deiry, W. S., T. Tokino, V. E. Velculescu, D. B. Levy, R. Parsons, J. M. Trent, D. Lin, W. E. Mercer, K. W. Kinzler, and B. Vogelstein. 1993 WAF1, a potential mediator of p-53 tumor suppression. Cell. 75:817-825.

21. Polyak, K., M. H. Lee, H. Erdjument-Bromage, A. Koff, J. M. Roberts, P. Tempst, and J. Massague. 1994. Cloning of p27 Kipl, a cyclin-dependent kinase inhibitor and a potential mediator of extracellular antimitogenic signals. Cell. 78:59-66.

22. Toyoshima, H., and T. Hunter. 1994. p27, a novel inhibitor of G1 cyclinCDK protein kinase activity, is related to p21. Cell. 78 (67-74).

23. Matthias, P., and I. Herskowitz. 1994. Joining the complex: cyclin-dependent kinase inhibitory proteins and the cell cycle. Cell. 79:181-184.

24. Dulic, V., W. K. Kaufmann, S. J. Wilson, T. D. Tlsty, E. Lees, J. W. Harper, S. J. Elledge, and S. I. Reed. 1994. p-53-dependent inhibition of cyclindependent kinase activities in human fibroblasts during radiation-induced G1 arrest. Cell. 76:1013-1023.

25. El-Deiry, W. S., J. W. Harper, P. M. O’Connor, V. E. Velculescu, C. E. Canman, J. Jackman, J. A. Pietenpol, M. Burrell, D. E. Hill, Y. Wang, and B. Vogelstein. 1994. WAF1/CIP1 is induced in p53-mediated G1 arrest and apoptosis. Cancer Res. 54:1169-1174

26. Li, R., S. Waga, G. J. Hannon, D. Beach, and B. Stillman. 1994. Differential effects by the p21 CDK inhibitor on PCNA-dependent DNA replication and repair. Nature (Lond.) 371:534-537.

27. Zhang, H., G. J. Hannon, and D. Beach. 1994. p21 containing cyclin kinases exist in both active and inactive states. Genes \& Dev. 1750-1758.

28. Waga, S., G. J. Hannon, D. Beach, and B. Stillman. 1994. The p21 inhibitor of cyclin-dependent kinases controls DNA replication by interaction with PCNA. Nature (Lond.). 369:574-578.

29. Flores-Rozas, H., Z. Kelman, F. B. Dean, Z. Q. Pan, J. W. Harper, S. J. Elledge, and M. O'Donnell, J. Hurwitz. 1994. CDK-interacting protein 1 directly binds with proliferating cell nuclear antigen and inhibits DNA replication catalyzed by the DNA polymerase. Proc. Natl. Acad. Sci. USA. 91:8655-8659.

30. Luo, Y., J. Hurwitz, and J. Massague. 1995. Cell-cycle inhibition by independent $\mathrm{CDK}$ and PCNA binding domains in $\mathrm{p}_{2} 1^{\mathrm{Cip1}}$. Nature (Lond.). 375:159-161.

31. Kim, D. W., T. Harada. I. Saito, and T. Miyamura. 1993. An efficien expression vector for stable expression in human liver cells. Gene. 134:307-308.

32. Tripathy, S. K., E. Goldwasser, M.-M. Lu, E. Barr, and J. M. Leiden. 1994. Stable delivery of physiologic levels of recombinant erythropoietin to the systemic circulation by intramuscular injection of replication-defective adenovirus. Proc. Natl Acad Sci. USA 91:11557-11561.

33. Kozarsky, K., MM. Grossman, and J. M. Wison. 1993. Adenovirus-mediated correction of the genetic defect in hepatocytes from patients with familial hypercholesterolemia. Somat. Cell Mol. Genet. 19:449-458.

34. Blank, R. S., M. M. Thompson, and G. K. Owens. 1988. Cell cycle versus 
density dependence of smooth muscle alpha actin expression in cultured rat aortic smooth muscle cells. J. Cell Biol. 107:299-306.

35. Owens, G. K., A. Loeb, D. Gordon, and M. M. Thompson. 1986. Expression of smooth muscle-specific $\alpha$-isoactin in cultured vascular smooth muscle cells: relationship between growth and cytodifferentiation. J. Cell Biol. 102:343352.

36. Clowes, A. W., M. A. Reidy, and M. M. Clowes. 1983. Kinetics of cellula proliferation after arterial injury. I. Smooth muscle growth in the absence of endothelium. Lab Invest. 49:327-333.

37. Wang, C.-Y., B. Petryniak, C. Thompson, W. Kaelin, and J. M. Leiden. 1993. Regulation of an Ets-related transcription factor, Elf-1 by binding to the retinoblastoma protein. Science (Wash. DC.) 260:1330-1335.

38. Lindner, V., N. E. Olson, A. W. Clowes, and M. A. Reidy. 1992. Inhibition of smooth muscle cell proliferation in injured rat arteries. J. Clin. Invest. 90:20442049.

39. Guzman, R. J., E. A. Hirschowitz, S. L. Brody, R. G. Crystal, S. E Epstein, and T. Finkel. 1994. In vivo suppression of injury-induced vascular smooth muscle cell accumulation using adenovirus-mediated transfer of the herpe simplex virus thymidine kinase gene. Proc. Natl. Acad. Sci. USA. 91:1073210736.

40. Chang, M. W., T, Ohno, D. Gordon, M.-M. Lu, G. J. Nabel, E. G. nabel, and J. M. Leiden. 1995. Adenovirus-mediated transfer of the herpes simplex viru thymidine kinase gene inhibits vascular smooth muscle cell proliferation and neointima formation following balloon angioplasty of the rat carotid artery. $\mathrm{Mol}$. Med. 1:172-181.

41. Steinman, L. 1995. Escape from "horror autotoxicus:" pathogenesis and treatment of autoimmune disease. Cell. 80:7-10.

42. Bishop, J. M. 1991. Molecular themes in oncogenesis. Cell. 64:235-248.

43. Heintz, N. 1993. Cell death and the cell cycle: a relationship between transformation and neurodegeneration? Trends Biochem. Sci. 18:157-159.

44. Speir, E., R. Modali, E. S. Huang, M. B. Leon, F. Shawl, T. Finkel, and S. E. Epstein. 1994. Potential role of human cytomegalovirus and p53 interaction in coronary restenosis. Science (Wash.). 265:391-394.

45. Thornton, M. A., A. R. Gruntzig, J. Hollman, S. B. King, and J. S. Gouglas. 1984. Coumadin and aspirin in prevention of recurrence after transluminal coronary angioplasty: a randomized trial. Circulation. 69:721-727.
46. MERCATOR Study Group. 1992. "Does the new angiotensin converting enzyme inhibitor cilazapril prevent restenosis after percutaneous translumina coronary angioplasty" Results of the MERCATOR study: a multicenter, randomized double-blind placebo controlled trial. Am. Heart. 117:777-782.

47. Ellis, S. G., G. S. Roubin, J. Wilentz, J. S. Douglas, and S. B. King. 1989. Effect of the 18-24 hour heparin administration for prevention of restenosis after uncomplicated coronary angioplasty. Am. Heart. 117:777-782

48. Landau, C., R. A. Lange, and L. D. Hillis. 1994. Percutaneous transluminal coronary angioplasty. N. Engl. J. Med. 330:981-993.

49. Muller, D. W., S. G. Ellis, and E. J. Topol. 1991. Colchicine and antineoplastic therapy for the prevention of restenosis after percutaneous coronary interventions. J. Am. Coll. Cardiol. 17 (Suppl B):126B-131B.

50. Simons, M., E. R. Edelman, J. L. DeKeyser, R. Langer, and R. D. Rosenberg. 1992. Antisense c-myb oligonucleotides inhibit intimal arterial smooth muscle cell accumulation in vivo. Nature (Lond.). 359:67-70.

51. Morishita, R., G. H. Gibbons, K. E. Ellison, M. Nakajima, L. Zhang, Y Kaneda, T. Ogihara, and V. J. Dzau. 1993. Single intraluminal delivery of antisense cdc2 kinase and proliferating-cell nuclear antigen oligonucleotides results in chronic inhibition of neointimal hyperplasia. Proc. Natl. Acad. Sci. USA. 90:84748478.

52. Ohno, T., D. Gordon, H. San, V. J. Pompili, M. J. Imperiale, G. J. Nabel, and E. G. Nabel. 1994. Gene therapy for vascular smooth muscle cell proliferation after arterial injury. Science (Wash. DC). 265:781-784.

53. Cohen, A. J., B. Weiser, Q. Afzal, and J. Fuhrer. 1990. Ventricular tachycardia in two patients with AIDS receiving ganciclovir. Aids. 4:807-809.

54. Faulds, D., and R. C. Heel, 1990. Ganciclovir: A review of its antiviral activity, pharmacokinetic properties and therapeutic efficacy in cytomegalovirus infections. Drugs. 39:597.

55. Epstein, S. E., E. Speir, and T. Finkel. 1993. Do antisense approaches to the problem of restenosis make sense? Circulation. 88:1351-1353.

56. Stein, C. A., and Y.-C. Cheng. 1993. Antisense oligonucleotides as therapeutic agents: Is the bullet really magical? Science (Wash. DC). 261:1004-1012.

57. Guzman, L. A., C. L. Garrel, E. J. Poptic, P. E. DiCorleto, and E. J. Topol. 1994. Despite in-vivo cellular and nuclear uptake, antisense oligonucleotides do not have a significant anti-proliferative effect after vascular injury. Circulation. 90:I-147. 